\title{
Using Debate to Maximize Learning Potential: A Case Study
}

Michael W. Firmin, (Email: firmin@cedarville.edu), Cedarville University Aaron Vaughn, Ph.D. Student, University of Vermont Amanda Dye, Ohio State University

\begin{abstract}
Following a review of the literature, an educational case study is provided for the benefit of faculty preparing college courses. In particular, we provide a transcribed debate utilized in a General Psychology course as a best practice example of how to craft a debate which maximizes student learning. The work is presented as a model for the principles of not building straw-men arguments, not shying away from controversial topics, giving politically-incorrect viewpoints fair treatment, making a crisp presentation that students will take seriously, and exemplifying gender-equity and aggressive female role-modeling. Reparative therapy and homosexual orientation was the debate's topic.
\end{abstract}

\section{REVIEW OF THE LITERATURE}

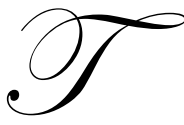

he utilization of debate as a classroom technique enjoys a relatively broad range of instructional fields where its application has shown success. That is, debating as a teaching exercise is not one where only instructors with a narrow band of subjects can employ the method. The research literature indicates that it has been found to be successful in fields such as business (Combs 1994), statistics (Shatz 1985), psychology (Moeller 1985), nutrition (Magnus 2000), political science (1980), sociology (Huryn 1986), mathematics (Alibert 1988), chemistry (Streitberger 1988), elementary education (Gibson 1994), nursing (Candela 2003), environmental science (Hadizedeh 2001), economics (Pernecky 1997), literature (Jackson 1990), and geography (Estaville 1988).

Debate protocol comes in many forms, and there does not appear to be one procedure which best suits all classroom venues. A traditional format typically contains first affirmative, first negative, second affirmative, and second negative speeches. These are followed by first negative, first affirmative, second negative, and second affirmative rebuttals. A vote by judges, in this case-class peers-may follow. However, instructors can construe a class debate using multiple variations, depending on factors such as the skill-level of the participants, experience, subject matter, learning objectives, and time parameters for completing the debate in a classroom setting. Pernecky (1997) suggests allowing ample time for class interaction, a component not typically found (obviously) in inter-varsity debate tournaments, for which adjustments also may be made in order to maximize learning potential among students.

Jackson (1990) suggests that the legalistic format of classroom debates is of secondary importance to accomplishing the pedagogical objectives of the classroom instructor. However, she also emphasizes the importance of delineating specific procedures that are clear to all participants and observers. In short, as long as the playing-field is level and the rules are fair, instructors can enjoy relatively wide latitude regarding the particular ground rules established. One author reported success, for example, using television talk show formats such as Oprah, Montel, and Jerry Springer as a basic paradigm - although more control was exercised in the classroom - and less hype-than typically one views in day-time television shows (Leonard 1999).

Whether using a parliamentary procedure or a more informal one, the role of the moderator is crucial for success in classroom debate. Maintaining general order, time keeping, points of order, and following prescribed rules are essential for the instructor to accomplish if a class debate is to be taken seriously by students and to keep the process from deteriorating into chaos or confusion. Of course, the professor can delegate the role of moderator (or 
chair) to a student in the class - but students generally will look to the instructor to keep the process running smoothly ("Using Taking Sides," 1997).

A number of techniques have been reported as successful in the literature regarding how professors can structure classroom debates. Rather than holding them in front of everyone in a large class, Dundes (2001) advocates using small group debates. Her experience has been that greater student participation occurs in such milieu. Watters (1996) uses the term "structured controversy" to describe this method, and emphasizes that debates in classroom settings must be carefully anchored to the subject matter being taught by the instructor. Students should be prepped from the first day of class when the syllabus is distributed, so that they know from the outset, what level of class participation will be required of them (Ryan 1995). Although debate, obviously, is a verbal exercise and graded accordingly, Estaville (1988) recommends that instructors require students to submit a two-to-four page position paper, with bibliography, during the class period prior to the debate in order to maximize students' background knowledge for what will be covered in the debate content.

A number of uses for classroom debate have been reported in the literature. These include starting class discussions on controversial or difficult topics (Frederick 1981), improving the skills that students bring to respective courses (Wentlaff 1988), sharpening argumentation skills (Sinonneaux 2002), teaching critical thinking (Leeman 1987), using debate as introductory exercises for other skills to be learned later in the course (McClish 1988), correcting deficiencies that students currently possess but need to improve during the course (Rothenberg, Fraser, and Berman 1980), and teaching ethical principles as part of specific course content (Michael \& Mitchell 2003). As a unifying theme debate appears to be one successful means of taking students from where they are at when they arrive in the class to a new level of skill or learning desired by the instructor.

Numerous benefits are reported in the literature for using debate in the college classroom. These include examining both sides of issues in a thorough and fair manner (Mooney 1991; Ingalls 1985), promoting gender equality and advancing feminist perspectives (Elliot 1993; Bruschke \& Johnson 1994; and Haffey 1993), promoting liberal art values in the curriculum (Rohrer 1987), improving student communication skills (Garrett, Hood, \& Schoener 1996), helping students to overcome their fears (Gersten 1995), increasing active student involvement in the learning process (Crone 1997), advancing critical thinking skills to new levels which likely could not be achieved via other methods (Colbert \& Biggers 1987), and empowering students to take responsibility for their own learning, rather than being instructor dependent (Frederick 1987). As a unifying theme, debate has the potential to free students by helping them to think for themselves, going beyond the finite limitation constraints of the course professor.

The literature contains some caveats for using debate in the classroom. Gilbert \& Eby (2001) note that the role of student demographics, teaching techniques, service learning, and creating trust and community in the classroom are salient factors in order for instructors to successfully use classroom debate. The traditional boundaries of the student-faculty relationship are atypical in debate settings, and instructors should assist students with debriefing and utilization of appropriate university services when warranted. Likewise, Goodwin (2003) notes that some ethnic groups or cultures may find debate to be incompatible with their preferred style of relating. Consequently, they may not profit from the experience, or earn the same high grades, as might students who are from cultures where confrontation is more normative. In sum, the instructors must exercise careful sensitivity when using debate in the classroom in order not to short-circuit the potential benefits for people whose personality or culture might find the teaching method to be aversive.

And finally, the literature indicates that assessing debates can be a particular challenge (Landrum 1991). The goals of debate in a collegiate classroom often are different from that of varsity or political debate. That is, the goal of debating in politics or varsity debating teams is to win. The ultimate aim is to receive a black or white conclusion, based on points, judging, or other methods - on how one's team ranked compared to the other teams participating (Rybacki \& Rybacki 1996). In contrast to this summative function, classroom instructors often have a formative assessment. In other words, the vote at the end of the debate may not be the professor's ultimate educational aim. Rather, the process of the debate, including the learning which occurred among and between the participating students, may be as important as the "voted" conclusion in terms of student assessment of learning. 
Obviously students are concerned about their grades. Mercadante (1988) suggests that student grades for debates should reflect the amount of time and effort students appear to have contributed, the general utilization of solid reasoning and critical thinking, application of the debate material to the course subject matter, and the apparent genuineness and diligence shown in preparation and delivery of the debate. It goes without saying that these are very subjective outcomes for assessment by the instructor. Empirical reports are mixed regarding the degree to which the skills acquired in debating are actually transferred to real life situations and vocational settings (Greenstreet 1993;; Malton \& Keele 1984; and Semlak \& Shields 1977), despite the anecdotal attestation by instructors who use the method in class (e.g., Magnus 2000). Peer ratings of student debates, overall, seem to show acceptable levels of validity (Smith 1990) when utilizing curriculum-based assessment procedures, although skill-based courses using interactive methods, in general, tend not to be effectively assessed via standardized instruments such as the ModelLearning Model Questionnaire or the Student Evaluation of Teaching Effectiveness (Young \& Young 1999).

\section{OBJECTIVE OF THE CASE STUDY}

With the literature review as a foundation, the debate included in the present article serves as a best-case practice example of what a quality debate looks like. That is, rather than describing a good classroom debate, this article sets forth a model of one. It is akin to a science professor showing colleagues how a successful classroom demonstration can be conducted or a medical professor showing physician educators how to teach a particular technique in rotation seminars to medical students. Describing the merits or even principles of the demonstration/ technique does not provide near the benefit of actually showing it. Obviously we can not fully recreate the debate used in class, but it was tape recorded and transcribed. We share it here in a slightly edited form due to journal space considerations but the bulk of it is intact as presented.

To help guide readers in making apt application to their own courses, we suggest the following six principles. First, try not to focus on the specific content of our particular debate. We are not suggesting that you use this particular one in your class. Although we believe the topic to be highly relevant across multiple disciplines, homosexuality is not the focus of this article. Rather, we are using this content to illustrate some salient points of making debate to be a successful classroom teaching technique.

Second, do not build straw men when using classroom debate. Students should be sufficiently challenged in an intellectually honest manner from all sides of the question being posed. Lopsided presentations or shoddy arguments by a particular view do not enhance student learning. We believe our example posed for your reading illustrates how this can be done effectively in a class setting. As you read the transcript, pay attention to the sharpness of both sides being presented and the forceful argumentation used by both the affirmative and negative cases. Students leaving class should feel that both sides of the argument presented received fair and balanced attention.

Third, do not shy away from controversial topics. There are more sensitive subject matters in academe today than gay issues. However, there are not too many of them. Professorial coverage of controversial material in lecture format may draw student objections of bias by the professor. However, student-generated debates on the same topic tend to lower student defenses and result in them hearing the material with more open ears and truly intellectual perspectives.

Fourth, give politically-incorrect viewpoints fair treatment. Instruction does not occur in a value-free context. We all have our biases and are prone to evangelize others toward them and away from adopting views contrary to our pathos. However, the mission of higher education is open and free inquiry into truth, wherever that may take us. As such, we owe it to our students to present not only our own views honestly and fairly, but also the viewpoints of those with whom we strongly disagree. As you read the content of our particular debate, pay attention to our attempt at presenting all sides of the issue uprightly and with gusto-including the viewpoint which runs contrary to popular academic sentiment.

Fifth, make a crisp presentation that students will take seriously. This is not the content of the material, but rather the manner in which the presentation is made. If students are listening to something that sounds tossed together the week before it was presented, it does not command near the respect as a project that was generated over many 
hours and weeks of preparation. Our illustrated debate in this article exemplifies a presentation with obvious preparation, followed apropos parliamentary rules, and left students with the feeling that their time was well spent as they invested interest and attention to the arguments being made on both sides of a controversial issue.

Sixth, exemplify gender-equity and aggressive female role-modeling. We believe that female students profited from watching an assertive woman advance her arguments in a forceful and logical manner during this debate. It can be less cogent talking about the importance of females exercising healthy aggression than seeing the process modeled for them in a debate format. As you read our debate transcript, envision the secondary benefit of having a female go toe-to-toe with a male on equal intellectual footing in class and how that can benefit women students to assert their views in a healthy manner in a male dominated society.

The transcript of the debate follows, and we believe it will be a useful example as you formulate your own content-specific debates in your own university classrooms. There is truth to the adage that a picture can be worth a thousand words. The context was a large General Psychology course which is part of the general education curriculum in a private Midwest university. Follow the above six principles as you generate a template for using the technique as part of your course instruction.

\section{AFFIRMATIVE BRIEF}

My proposition is as follows: "Professional legal and ethic codes should permit mental health professionals to treat homosexuals experiencing mental anguish presenting from sexual orientation either toward an integrated homosexual orientation or toward a heterosexual orientation." I define the terms included in this proposition in the following way: Professional legal and ethic codes are codes set forth by professional organizations such as those stated by the American Psychiatric Association and the American Psychological Association. Mental health professionals encompass all of those professionals who would serve as a professional counselor, psychologist, psychiatrist, marriage and family counselor, pastoral counselor, etc. It may be defined as anyone whose professional expertise would be sought in making life decisions, or who would be consulted regarding a mental disorder or mental anguish.

Treatment would include psychotherapy, counseling, medication, etc. Homosexuals are defined as those who experience attraction, arousal, or affection toward members of the same sex, not necessarily those participating in acts of a sexual nature with same sex partners. Mental anguish is defined as any anxiety, guilt, depression, or otherwise presenting symptoms arising from cognitive dissonance, or mental discomfort. Sexual orientation will be defined as simply the sexual interest experienced by one toward another of a particular gender. Heterosexual orientation is defined as a sexual interest in members of the opposite sex resulting in attraction, arousal, and affection towards individuals of the opposite gender.

The problem stated by my position is that clients suffering mental anguish due to sexual orientation are having their rights to freedom of choice regarding treatment options infringed by the current legal and ethic codes set forth by professional organizations. Consequently, clients may not be receiving the best treatment available under current standards. Presently, the American Psychiatric Association (APA) has determined that homosexuality is no longer a diagnosable mental disorder as it used to be classified.

This change resulted in its removal from the Diagnostic and Statistical Manual of Mental Disorders (DSM). Following the decision to remove homosexuality from the DSM, legal and ethic codes were adjusted to prohibit counseling professionals from practicing conversion or reparative therapy in an attempt to bring an individual experiencing mental anguish due to a homosexual orientation to a heterosexual orientation.

This decision was supported by the rationale that it is the role of the therapist to act in the best interest of the client and given the relatively low success rate of reparative therapy, it was deemed unethical to practice this form of therapy. Therefore, currently, the only legal and ethical approach to treating homosexuals is integration. This seeks to bring individuals suffering mental anguish back to health by helping them to accept their new sexual orientation and its resulting lifestyle, and helping them to cope with and accept this part of what is now considered a normal 
healthy alternative. In light of this, an objective and concerned professional would be forced to make several inquisitions into the rationale supporting this current treatment approach.

First, one would be interested in knowing whether the APA was correct in having removed homosexuality from the DSM in the first place. It appears to me, and indeed to many at the time of the decision, that the APA did not act in the best interest of the public by removing homosexuality from the DSM. Rather, the APA caved to the agenda of a group of individuals who were at risk of losing their psychological licenses because they were closet homosexuals.

Eventually, they did convince many heterosexuals to their side; however, it is important to note that the movement began with a group who, according to those standards, were diagnosable mental patients who had a strong bias and very high stakes at risk when they pushed an agenda that would benefit their situation by helping their mental disorder come to be accepted as "normal."

Now, I pause here and remark that both mine and the opposing side agree that the DSM requires certain alterations according to changes in social standards. I say this because I am not arguing that the DSM should not be changed according to careful logical, well-articulated, and objective legislation; quite the contrary is true.

What I am differentiating is two things. First, we must be careful that legislation is passed only in the benefit of the patient and that it is approached from an objective position. Second, we should not leave a door open for any and all mental disorders to argue their way into normalcy.

Abnormality, by nature, is defined according to the culture in which one resides; however, I hope that you can see where I am going with this. Already, professional psychological journals and publications are calling into question the legitimacy of pedophilia as a disorder. Pedophilia is sexual activity between an adult and a child under fourteen years of age, or at least it was. Now pedophilia is understood by the field of mental health to be a disorder only if it causes the pedophile marked mental anguish. If then, a group of pedophiles were to organize themselves and to push their agenda through legislation in the same way as homosexuals did, are we ready to accept pedophilia as an acceptable alternative sexual lifestyle?

The act itself does not change, only the social attitude surrounding it. So what then makes it no longer a disorder? I find very strong similarities between the other sexual dysfunctions, paraphilias, image disorders, etc. and homosexuality. For instance, according to the DSM, paraphilias are characterized by recurrent, intense sexual urges, and fantasies that cause clinically significant distress or impairment in social, occupational, or other important areas of functioning.

I find this description not far from the feelings expressed by those seeking out reparative therapy according to the case studies I've read. Furthermore, also according to the DSM, sexual dysfunctions are characterized by disturbances in sexual desire and in the psychophysiological changes that characterize the sexual response cycle and cause marked distress and interpersonal difficulty.

Again, this description shares many of the characteristics experienced by those who feel that they may be a homosexual, or consider themselves a homosexual and would prefer to live a heterosexual lifestyle. So again consider our first question: "Should homosexuality have been removed from the DSM in the first place, or does it remain too similar to other diagnosable sexual disorders to be considered both 'healthy' and 'normal'?"

I would leave that answer to further, more objective and qualitatively accurate investigation by professional organizations. The answer that I am willing to accept for myself, is that in a case where clients are experiencing marked mental anguish regarding their sexual orientation and wish to change some aspect of themselves, I consider this at least to be a diagnosable condition. After reaching a satisfactory answer to this question in one's own mind, subsequent issues arise in either case. 
If therapists were to decide that mental anguish presenting from sexual orientation should be treatable, as it now is in a narrow sense, then they would need to ask: "Is it being handled as judiciously as other psychological disorders?" In turn, if one supports the APA ruling that homosexuality is a viable lifestyle and should cause no marked mental anguish and that only the presenting symptoms of guilt, depression, and anxiety, should be treated the natural question is: "Are those symptoms being adequately and judicially treated as would other major life decisions or adjustment issues?" Let me consider each of these questions independent of the other.

First, if mental anguish presenting from sexual orientation were to be considered a diagnosable disorder, then it would be expected to be treated as the other diagnosable disorders. Clearly, this is not the current status. Counselors are limited to one treatment option when a homosexual enters their office-integration, which as before mentioned, is an incorporation of the homosexual orientation.

Do professional counselors take this approach with any other disorder? Certainly such a narrow approach is not utilized with presenting problems such as depression. If individuals suffering depression seek professional treatment, they will be presented with a smorgasbord of treatment approaches ranging from traditional psychotherapy and medication to electro-convulsive therapy, and a plethora of alternative therapies ranging from religious-based endeavors, adventure-based safaris, and possibly acupuncture or even dance lessons.

The same approach is true with anxiety. Ethical codes do not limit a person suffering from generalized anxiety disorder by simply forcing them into psychotherapy. Although clinical research suggests that it is a more effective long-term treatment than medication with this particular disorder, individuals are still given the opportunity to explore treatment options and choose the one that is best suited for them.

The solution to this dichotomy would be fairly simple. Although we acknowledge that reparative therapy has traditionally had a lower success rate than integration, thus far, professional legal and ethic codes could be adjusted to give the counselor and client the option, should the client choose, to attempt reparative therapy. In addition, further research should be committed to finding alternate successful treatments for homosexuals experiencing mental anguish and preferring to pursue a heterosexual lifestyle.

This seems only reasonable given the fact that every other treatable psychological disorder allows the client a variety of treatment approaches, all of which find some merit in at least a minimal number of cases. I have read numerous case studies of variant types of homosexuals who found immense satisfaction as a heterosexual after undergoing reparative therapy. Despite the marginal number of people emerging successful from reparative therapy, 99\% of clients who have attempted it say that they believe it has merit and 95\% of therapists who have attempted to counsel people with it believe that it holds value.

If our profession is willing to allow psychologists to admit acupuncture, meditation, prayer, and other alternative therapies that prove effective only a fraction of the time, then how could we justify making a practice unethical that may provide immense gratification and alleviation of mental anguish to some clients?

I will now move along to the alternate side of the question. If you hold the opinion, as many do, that homosexuality was rightly removed from the DSM and should therefore no longer be treated as a psychological disorder, what issues are to be considered? If homosexuality is a viable life choice, equal with decisions concerning occupation, living arrangements, adjustment issues, etc. is it being treated equitably with other synonymous cases?

Again I would have to argue that it is not. As an illustration, imagine that I were a trial lawyer, who had been practicing for 25 years, and suddenly found myself experiencing great mental anguish, cognitive dissonance, and guilt because I was afraid that during the course of my career I had unjustly placed many innocent people behind bars and allowed many guilty offenders to walk the streets free. Upon this horrifying realization I decided to visit a vocational counselor to either receive alleviation from my guilt by re-justifying my career as a trial lawyer or to receive counsel in how to change my career to one that would cause me less mental anguish. 
Clearly, there are at least two options before me, if not an infinite number of alternatives. How then, if homosexuality is to be considered an equally viable life choice, could we limit professionals offering assistance in making a life choice, to only one option in which to direct their clients. A far greater question follows: "How could professional organizations consider under their sovereignty the right to decide that every single homosexual seeking treatment is intended to live a homosexual lifestyle?"

That would be as unjust as limiting vocational counselors to the only treatment option of convincing every client that came into their office that the career in which they presently found themselves was the only one suited to them and then making them come to terms with their assigned duty. This point I think needs far less explaining than the previous, and proves equally easy to resolve.

I propose that a client and counselor be given the opportunity to sit down upon their initial session and discuss the goals of therapy, laying forth all options available, then allowing the client the freedom to choose either integration or conversion with the full understanding that conversion is historically more difficult to accomplish. I guess the real question that we have to ask ourselves is why we haven't so far been persuaded that these healthy, wellfunctioning, members of society are competent enough to make that decision for themselves and why we have persistently forced them into a lifestyle without allowing them the opportunity to explore all alternatives available to them?

In summary, I want to point out the fact that, although this discussion is typically seen as a battle of moral issues, it really boils down to much more pragmatic and tangible questions. Granted, any belief system or worldview is going to color the lens through which the issue is viewed; however, if we can set aside those lenses for a moment we will see that it need not be the case.

I ask specifically Christians to set aside their lens of morality which tend to cause them to view homosexuality as a sin; I ask evolutionary psychologists to set aside their lens of reproduction and survival which will inevitably cause them to view homosexuality as a useless relationship in that it has very little chance of passing on genetic material; I ask homosexuals to set aside their lens that potentially directs them to adamantly defend and justify a lifestyle in which they so often undergo persecution; and I ask all of us to look to our true calling as counselors and therapists which is of course for the good of the client.

\section{NEGATIVE BRIEF}

The affirmative case presented several definitions regarding some of the terms utilized within the affirmative argument. The negative case proposes an alternative definition for sexual orientation. The affirmative team stated: "Sexual orientation is simply the sexual interest experienced by one individual toward another of a particular gender." The negative team proposes the following alternative definition for sexual orientation: "An enduring emotional, romantic, sexual, or affectionate attraction to another person existing along a continuum, ranging from exclusive homosexuality to exclusive heterosexuality; it refers to feelings and self-concept; it results from a complex interaction of environmental, cognitive, and biological, factors and is shaped at an early age."

In 1973, the American Psychiatric Association (APA) removed homosexuality from its list of disorders. The APA's Committee on Nomenclature reviewed numerous studies that used standardized instruments and non-patient populations showing that most gay persons were satisfied with their sexual orientation and were not impaired in their social functioning.

In the past, defining homosexuality as an illness buttressed society's moral opprobrium of same-sex relationships. In the current social climate, all research points to claiming acceptance of homosexuality as a normal variant of human sexuality. Recent publicized efforts to repathologize homosexuality by claiming that it can be cured are often guided, not by rigorous scientific or psychiatric research, but many times by religious and political forces opposed to full civil rights for gay men and lesbians. 
The medical model inherited from physical medicine tempts us to think in terms of categories of disease and health as if they were mutually exclusive. Various criteria are used to determine what situations are suitable for therapeutic interventions including: personal unhappiness, concerns of other people, dysfunction-an inability to carry out one's functions in an effective, self-enhancing manner, legal and community problems, and danger to oneself or to others.

Homosexuals, as a group, do not adhere to these definitions of abnormality, except in cases of societal disapproval. They are not inherently unhappy, only those friends or associates who consider homosexuality as wrong show concern. Also, homosexuals are more than able to adequately perform essential functions. All legal and community problems stem from society's rejection of their lifestyle rather than the lifestyle itself, and the issue of homosexuality does not make one a danger to oneself or others.

In the DSM there is a classification for a Sexual Disorder, not otherwise specified, which includes conditions of "persistent and marked distress about one's sexual orientation." This allows for those who are truly experiencing major disturbance over their sexual orientation whether that be homosexual, bisexual, or heterosexuality to receive a diagnosis, and consequently, psychotherapeutic treatment.

The current debate surrounding homosexuality inevitably involves the use of reparative therapy. I begin my argument against reparative therapy by the very name of the theory reparative. Immediately, the connotation is presented to the client that something is to be fixed, that maladaptation has occurred, and he or she is inherently "sick."

However it has been shown and verified that there is no pathology to be cured or repaired or "converted." The very goal of the treatment stigmatizes and adds to the distress being caused to the individual for which he or she sought counseling! This is in direct violation of the medical edict to first, do no harm. These psychotherapeutic modalities that seek to convert or "repair" homosexuality are based on developmental theories whose scientific validity is questionable at best.

Furthermore, "anecdotal" reports of "cures" are counterbalanced by anecdotal claims of psychological harm. In the last four decades "reparative" therapists have produced no rigorous scientific research to substantiate their claims of cure. "Reparative" therapy tends to overstate the treatment's accomplishments while neglecting any potential risks to patients.

Homosexuality has not been proven to cause significant distress in and of itself. The social stigmatization and the negative views imparted on one who follows a homosexual lifestyle would cause significant distress in any of our lives. Of course, the natural desire of social beings is to be accepted. Many times this force for acceptance pushes homosexuals to try and change simply to alleviate the feelings of anxiety and mental anguish being experienced.

This does not, however, give therapists the right to supercede the well-being of the individual for the belief system of the therapist. People who have deluded themselves into believing their own perception of truth as the only possible mode in which truth can exist are shortsighted and narrow-minded. The militant Islamic sect which allows for and encourages such acts as 9/11 fully believe that they are inherently right and others will conform to their truth. The very belief in something does not necessitate that being true. People cannot use their belief systems, based on no empirical evidence nor objectivity, to justify a course of action when dealing with the lives of human beings. Reparative therapy seeks to do just that.

One's worldview should not become a force in violating ethical and legal codes already set in place, especially when the reasoning behind violating those codes is baseless in scientific research, and has been proven to cause significant harm in a large number of cases. Who are we as human beings to deign exactly what truth is to another human being? Again, sexual orientation stems from a complex interaction of environmental, cognitive, and biological factors. 
Allow me to dissect the affirmative case presented in argument for change. First, the affirmative case stated that clients experiencing mental anguish are being restricted in their rights to freedom of choice in treatment. The question one must ask is how can this be true? How can people have their freedom restricted when the only restriction is to an unfeasible and detrimental alternative therapy that in the large majority of cases causes more harm than good and directly contradicts all research data surrounding the argument?

The affirmative's second point was that consequently clients may not be receiving the best treatment available under current standards. Obviously the reverse of this has been proven true and to propose the opposite is preposterous. Second, the affirmative case argued that the change that came about in 1973 was brought about by "caving into the agenda of a group of individuals...closet homosexuals." However as the negative case has already proven, the APA Committee on Nomenclature reviewed significant non-partisan research involving standardized research and non-patient populations to reveal the actual status of functioning homosexuals.

Third, the affirmative did present one point to which I will wholeheartedly agree. However, this point lies in direct contradiction to the very essence of the affirmative cases' solution to the problem which they posit exists. The affirmative case stated: "We must be careful that legislation is passed only in the benefit of the patient and that it is approached from an objective position." This statement must be and has been followed to the letter by the APA. However, the very nature of homosexual diagnosis as a pathology violates this very principle which the affirmative team espouses. To legislate homosexuality back to pathological disease or to even simply give the option of reparative therapy are statements that could only be made from a subjective position.

As I stated earlier the very root of the word "reparative" emphasizes a problem which must be corrected. If the clients cannot change (as has been proven in case after case), the rest of their lives are an unfixable, socially perverted meaningless existence. Their orientation, as we have also already proved, is unchangeable after an early age. They may only repress what are natural desires that they cannot alter.

Fourth, the affirmative case stated that all mental disorders may argue their way into normalcy. This view must then espouse a mutually exclusive definition of normalcy. The only options being considered are abnormality and normality. However, as countless studies have shown, abnormality is based on a continuum. That continuum does not change, but the social perception of that continuum can change.

The affirmative case then appealed to the moral nature of you the listeners to understand their case that all deviancy and "evil" may become "normal." We again have strayed from the objective nature of science and nomenclature and allowed this issue to become a moral decision based on belief systems deciding what is right and what is wrong.

Fifth, the affirmative case stated that the distress found in paraphilias including but not limited too-recurrent, intense sexual urges and fantasies that cause clinically significant distress impairment in social, occupational, or other important areas of functioning - were very similar to the same distresses experienced by those desiring reparative therapy. The affirmative case then used this example to justify the use of reparative therapy. Again, as I have aforementioned the APA has already included a diagnosis for these distresses and does not distinguish between those stressors being experienced by a homosexual or heterosexual. The studies have shown that an integration of that individual's sexual orientation which has been in place since early childhood, before any sexual experiences have occurred, is the only treatment plan adequately solving the mental anguish being felt.

Sixth, the affirmative case then restates the need for a diagnosable condition in the DSM. Again, I ask the affirmative case to simply review the DSM and they will immediately see the sexual disorder, not otherwise specified, which includes: "persistent and marked distress about one's sexual orientation."

Seventh, the affirmative then went on to assume that if the mental anguish experienced from sexual orientation were a diagnosable disorder (which is in fact true) then it is in fact being treated "unfairly" because of the limit of treatments as compared to depression and anxiety disorders. I then simply ask the question, what other treatments have been presented with the backing of success from rigorous scientific study as the treatment options for 
depression and anxiety disorders have been proven? Until viable treatment options have been found and researched (and I sincerely hope that these options soon become available) then it is unethical to simply postulate that an unproven, generally unsuccessful, and realistically harmful plan of treatment can be considered a practical alternative.

Eighth, the affirmative case then stated that further research should be committed to finding alternative successful treatments. I wholeheartedly agree with this statement; however, I also am aware that parties on both sides of this issue have been rapaciously pursuing this exact research for the past 25 years.

Nineth, the affirmative case then based the remainder of their argument surrounding reparative therapy and its citing of "numerous cases" resulting in success or perceived success in "converting" the homosexuals. However, in the very next sentence the affirmative case stated: "Despite the marginal number of people emerging successful from reparative therapy..." I ask only one question in response to this remark: "What is the internal validity and research value in the "anecdotal" case studies? These examples are sketchy at the very best, much less to be used as an argument in professional circles.

Tenth, the affirmative case last presented that if there are alternatives to other diagnoses, then it is unethical not to give alternative options to homosexuality. Again, immediately the assumption is made that homosexuality is inherently a pathology. And again we see that even if it was a pathology, which it is not, there is no researched evidence supporting alternative treatment plans.

I agree with the conclusion set forth by the affirmative case, for each of us to look at our true calling as counselors and therapists for the good of the client. However, the conclusion one must inevitably come to is twofold.

First, homosexuality is not a pathology in and of itself; and second, when the situations surrounding one who is sexually orientated to a homosexual lifestyle drives that individual to experience prolonged mental anguish and distress, beyond that experienced by most all homosexuals because of societal rejection, then intense therapy integrating the acceptance of one's sexuality and allowing oneself to cognitively function successfully as a homosexual in a biased, prejudiced and sadly discriminatory world is the only ethically feasible and successful course of action to be taken.

\section{REBUTTAL TO THE NEGATIVE CASE}

The negative case asserts that the only restriction being made of those seeking treatment, is from a harmful treatment. However, I wonder how those who have received immense satisfaction from conversion therapy would respond. True, reparative therapy may seem to be successful in only a margin of cases, but how is this different from so many forms of therapy used to treat depression. Electroconvulsive therapy (ECT), while posing great potential harm to its subjects, is still viewed as a viable and even praise-worthy form of treatment for some clients.

The negative case also finds fault in the term "reparative therapy." The name of the therapy is irrelevant. What is important is that individuals seeking counseling have the option either toward integration into a homosexual OR heterosexual lifestyle. If the negative case prefers, they may use the synonymous term "conversion therapy" for their conscience sake.

The affirmative case acknowledges the DSM classification "Sexual Disorder not otherwise specified." The problem here again is the restriction of treatment. Even if a homosexual experiencing distress over their sexual orientation were to seek treatment and be assigned the classification "Sexual Disorder not otherwise specified" they would still be forced into a homosexual lifestyle without being given the option of their therapist counseling them toward an integrated heterosexual lifestyle.

The negative case stressed that there were no viable alternate therapies to integration. First of all, while having a lower success rate than integration, reparative therapy does see success in some people, therefore making it a viable treatment option. Second, the APA's preemptive removal of homosexuality from the DSM significantly inhibited the possibility of improving upon reparative therapy and finding other alternate therapies. All research 
requires money, and funds are not distributed to research conditions no longer considered diagnosable. Therefore, the possibility for more effective treatments has been squelched.

The purpose of the affirmative case is not to convert all homosexuals to heterosexuality, nor to inflict further mental anguish on those seeking treatment. The pure and simple purpose of the affirmative case is to present those in need with an array of treatment methods of varying outcomes, methodologies, and success rates. Each treatment method is unique and each reaches various individuals in more or less effective measures. Therefore, all treatments with the possibility to allay the condition causing mental anguish should be weighed in the balance when choosing a course of treatment.

\section{REBUTTAL TO THE AFFIRMATIVE CASE}

May I again clarify the key point underlying this entire debate? That key issue surrounds the inherent "pathology" supposedly found within the homosexual. As I have previously stated, a substantial majority of homosexuals who accepted their orientation displayed no pathology as should be found within the psyche of one experiencing marked and persistent mental distress.

Outside of what would be considered typical adjustment stressors, especially stressors found within a society that many times is hostile to the lifestyle chosen, the homosexual lives a typical and "normal" lifestyle. Conversely, "reparative" therapy contradicts this very fact. Reparative therapy seeks to "fix" someone living a homosexual lifestyle. This therapy modality seeks to alter the very personality of the individual. These types of treatments can be extremely dangerous for the client.

Again, the affirmative argument stated that based on these findings pathologies may "argue" their way into normalcy. The affirmative team is again beginning with the assumption that homosexuality is inherently pathological and has argued itself into normalcy. However, as the negative argument has stated, homosexuality is not a pathology and never was. Societal restraints and moral opprobrium had simply banished it into abnormality. This was inherently mistaken; it has been and continues to be corrected.

Above all, I believe that all possible alternatives must be researched in order to obtain the utmost benefit for the mental, social, and physical health of all those around me, regardless of orientation. However, one cannot violate the known research in order to further his/her subjective, moral belief systems. This is exactly the approach reparative therapists take in order to accomplish their own personal goal. Current treatment modalities, explicitly the integration of the client's orientation into society, have proven to be effective and beneficial. This viable treatment option allows homosexuals and heterosexuals to better cope and deal with their environment. Reparative does not accomplish these goals.

As treatment options continue to be researched and implemented, each of us must respond to our calling of helping to better the lives of those around us as researchers, therapists, counselors, teachers, etc. We also must realize differing sexual orientation as normal "set" variants. We must not allow alternative therapy coming directly from a subjective modality to force people to reject their inherent orientations whether that be homosexual, heterosexual, bisexual, or transsexual.

\section{REFERENCES}

1. Alibert, D. 1988. Towards new customs in the classroom. For the Learning of Mathematics-An International Journal of Mathematics Education 8:31-35, 43.

2. Bruschke, J. and A. Johnson. 1994. An analysis of differences in success rates of male and female debaters. Argumentation and Advocacy 30:162-173.

3. Candela, L. 2003. Ethical debates: Enhancing critical thinking in nursing students. Nurse Educator 28:37-39.

4. Colbert, K. and T. Biggers. 1987. Why should we support debate? In Advanced debate: readings in theory, practice, \& teaching 3rd ed., ed. D. Thomas and J. Hart, Chap. 1. Lincolnwood, IL: National Textbook Co. 
5. Combs, H. W. and S. G. Bourne, S.G. 1994. The renaissance of educational debate: Results of a five-year study of the use of debate in business education. Journal on Excellence in College Teaching 5:57-67.

6. Commander, N. E. 1994. Ideas in practice: Debate as an active learning strategy. Journal of Developmental Education 18:22-24.

7. Crone, J. A. 1997. Using panel debates to increase student involvement in the introductory sociology class. Teaching Sociology 25:214-218.

8. Dundes, L. 2001. Small group debates: Fostering critical thinking in oral presentations with maximal class involvement. Teaching Sociology 29:237-243.

9. Elliot, L. B. 1993. Using debates to teach the psychology of women. Teaching of Psychology 20:35-38.

10. Estaville, L. E. 1988. Debate: A teaching strategy for geography. Journal of Geography 87:2-4.

11. Frederick, P. 1981. The dreaded discussion: Ten ways to start. Improving College and University Teaching 29:109-114.

12. Frederick, P. J. 1987. Student involvement: Active learning in large classes. New Directions for Teaching and Learning 32:45-56.

13. Garrett, M., L. Hood, and L. Schoener. 1996. Debate: A teaching strategy to improve verbal communication and critical-thinking skills. Nurse Educator 21:37-40.

14. Gersten, K. 1995. Debating the research paper. Journal of Adolescent \& Adult Literacy 39:71-72.

15. Gilbert, P. R. and K. K. Eby. 2001. Blowing the teachers away: Teaching controversial and sensitive issues to undergraduates. Journal on Excellence in College Teaching 12:37-54.

16. Goodwin, J. 2003. Students' perspectives on debate in content area classes. Communication Education 52:157-163.

17. Greenstreet. 1993. Academic debate and critical thinking: A look at the evidence. National Forensic Journal 11:13-28.

18. Hadizadeh, J. 2001. An interdisciplinary course centered on student debate of current environmental issues. Journal of Geoscience Education 49:44-49.

19. Haffey, D. B. 1993, April. A problem-solving analysis of women in debate. Paper presented at the 1993 joint meetings of the SSCA \& the CSCA. Lexington, KY.

20. Huryn, J. S. 1986. Debating as a teaching technique. Teaching Sociology 14:266-269.

21. Ingalls, Z. 1985, May 8. Resolved, that competition in college debate is as fierce as in a basketball playoff game. The Chronicle of Higher Education, pp. 13-14.

22. Jackson, B. L. 1990. Debating Huck Finn. College Teaching 38:63-66.

23. Landrum, R. E. 1991. Student evaluation of classroom debates. College Student Journal 25:163-165.

24. Leeman, R. W. 1987, November 5-8. Taking perspectives: Teaching critical thinking in the argumentation course. Paper presented at the annual meeting of the Speech Communication Association, Boston, MA. ERIC ED292147

25. Leonard, J. 1999, September. From monologue to dialogue: Facilitating classroom debate in mathematics methods courses. Paper presented at the Joint Annual Meeting of the School Science and Mathematics Association and the North Carolina Council of Teachers of Mathematics, Greensboro, NC. ERIC ED441696

26. Magnus, M. H. 2000. Using a debate to teach food aid. Journal of Nutrition Education, 32, 119A-119A2.

27. Matlon, R. J. and L. M. Keele. 1984. A survey of participants in the national debate tournament, 1947-1980. Journal of the American Forensic Association 20:194-205.

28. McClish, G. 1988, March. Controversy in the composition classroom: Debate as a mode of pre-writing. Paper presented at the annual meeting of the Conference on College Composition and Communication, St. Louis, MO. ERIC ED 295189.

29. Mercadante, R. A. 1988, March. Formal debate as a pedagogical tool in college classroom. Paper presented at the National Seminar on Successful College Teaching, Orlando, FL. ERIC ED384943

30. Michael, S. R. and S. Mitchell. 2003. Enhancing critical thinking in nursing students. Nurse Educator 28:3739.

31. Moeller, T. G. 1985. Using classroom debates in teaching developmental psychology. Teaching of Psychology 12:207-209.

32. Mooney, C. J. 1991, March 13. Foes share a classroom to help students examine both sides of the abortion debate. The Chronicle of Higher Education, pp. A15, A18.

33. Pernecky, M. 1997. Debate for the Economics class-and others. College Teaching 45:136-138. 
34. Rohrer, D. M. 1987. Debate as a liberal art. In Advanced debate: Readings in theory, practice, \& teaching 3rd ed., ed. D. Thomas and J. Hart, chap. 2. Lincolnwood, IL: National Textbook Co.

35. Rothenbert, I. F. and J. S. Berman. 1980. College debate and effective writing. Teaching Political Science 8:21-39.

36. Ryan, C. 1995, March. Debate is perfect for integrated skills. Paper presented at the Annual Meeting of Teachers of English to Speakers of Other Languages, Long Beach, CA. ERIC ED390304

37. Rybacki, K. C. and D. J. Rybacki. 1996. Advocacy and opposition: An introduction to argumentation. Boston: Allyn \& Bacon.

38. Semlak, W.D. and D. C. Shields. 1977. The effect of debate training on student's participation. The Journal of the American Forensic Association 13:194-196.

39. Shatz, M. A. 1985. The Greyhound strike: Using a labor dispute to teach descriptive statistics. Teaching of Psychology 12:85-86.

40. Simonneaux, L. 2002. Analysis of classroom debating strategies in the field of biotechnology. Journal of Biological Education 37:9-12.

41. Smith, R. A. 1990. Are peer ratings of student debates valid? Teaching of Psychology 17: 188-189.

42. Streitberger, H. E. 1988. A method for teaching science, technology, and societal issues in introductory high school and college chemistry classes. Journal of Chemical Education 65:60-61.

43. Taking sides: Using taking sides in the classroom. 1997. Guilford, CT: McGraw-Hill.

44. Watters, B. L. 1996. Teaching peace through structured controversy. Journal on Excellence in College Teaching, 7, 107-125.

45. Wentzlaff, S. L. 1988, February. Honors students and a basic speech-communication course: Techniques for meeting their needs. Paper presented at the Midwest Basic Course Directors Conference, Dayton, OH. ERIC ED297401

46. Young, C.O. and L. H. Young. 1999. Assessing learning in interactive courses. Journal on Excellence in College Teaching, 10, 63-76.

\section{NOTES}




\section{NOTES}

